\title{
Eco-environment Status Evaluation and Change Analysis of Qinghai Based on National Geographic Conditions Census Data
}

\author{
Min Zheng ${ }^{1,2}$, Maoliang Zhu ${ }^{1,2}$, Yuan Wang ${ }^{1,2}$, Changjun $\mathrm{Xu}^{1,2}$, Honghai Yang ${ }^{1,2}$ \\ ${ }^{1}$ Provincial Geomatics Center of Qinghai, Xining, China; \\ ${ }^{2}$ Geomatics Technology and Application key Laboratory of Qinghai Province, Xining, China;
}

KEY WORDS: national geographic conditions census, remote sensing, eco-environment status, ecological index, ecological change analysis

\begin{abstract}
:
As the headstream of the Yellow River, the Yangtze River and the Lantsang River, located in the hinterland of Qinghai-Tibet Plateau, Qinghai province is hugely significant for ecosystem as well as for ecological security and sustainable development in China. With the accomplishment of the first national geographic condition census, the frequent monitoring has begun. The classification indicators of the census and monitoring data are highly correlated with Technical Criterion for Ecosystem Status Evaluation released by Ministry of Environmental Protection in 2015. Based on three years' geographic conditions data (2014-2016), Landsat-8 images and thematic data (water resource, pollution emissions, meteorological data, soil erosion, etc.), a multi-years and high-precision eco-environment status evaluation and spatiotemporal change analysis of Qinghai province has been researched on the basis of Technical Criterion for Ecosystem Status Evaluation in this paper. Unlike the evaluation implemented by environmental protection department, the evaluation unit in this paper is town rather than county. The evaluation result shows that the eco-environment status in Qinghai is generally in a fine condition, and has significant regional differences. The eco-environment status evaluation based on national geographic conditions census and monitoring data can improve both the time and space precision. The eco-environment status with high space precise and multi-indices is a key basis for environment protection decision-making.
\end{abstract}

\section{INTRODUCTION}

Located in the hinterland of Qinghai-Tibet Plateau, Qinghai province is hugely significant for ecosystem as well as for the maintenance of ecological security and sustainable development in China. The Yangtze, Huang Rever and LancangRever which is most important river in China are originated from Qinghai. Three-river source region not only supplies 60 billion cubic meters of water to the downstream each year, but also maintains eco-environment security of China and neighboring countries through the atmospheric circulation and river water cycle.(Jia, 2011) Qinghai lake basin is a natural barrier to prevent the western from desert spreading from the eastern, and is an important node to maintain ecological security in the northeast of Qinghai-Tibet Plateau. The melting of the glaciers in Qilian Mountain moistens not only the Qilian Mountains in Qinghai Province, but also areas in Gansu Province and parts of Inner Mongolia. Qinghai is an ecological barrier for the regional sustainable development, and also has the most sensitive natural eco-system and fragile eco-environment. Eco-environment is the biggest advantage and potential of Qinghai. To protect the eco-environment of Qinghai is always the primary responsibility and historical responsibility of Qinghai.(Yang, 2017)

With the accomplishment of the first national geographic condition census, the frequent monitoring has begun. Both of census and monitoring has acquired a large amount of data which precisely reflect the geographic condition of Qinghai, and the classification indicators of the data are highly correlated with Technical Criterion for Ecosystem Status Evaluation released by Ministry of Environmental Protection in 2015.

The existing eco-environment status evaluation is mostly implemented on a small scale(Zhao et al. 2013; Bassett, 2015) and a fixed time, which can hardly reveal the spatial and temporal change of eco-environment status. Besides, the data for evaluation is acquired based on middle resolution remote sensing image interpretation which is not precise enough. Based on three years' geographic conditions data (2014-2016), Landsat- 8 images and thematic data (water resource, pollution emissions, meteorological data, soil erosion, etc.), a multi-years and high-precision eco-environment status evaluation and spatiotemporal change analysis of Qinghai province has been researched on the basis of Technical Criterion for Ecosystem Status Evaluation in this paper. Unlike the evaluation implemented by environmental protection department, the evaluation unit in this paper is town rather than county. The eco-environment status with higher space precise is a key basis for environment protection decision-making

\section{AREA OF EVALUATION}

Qinghai Province locates in the hinterland of Qinghai-Tibet Plateau. The highest elevation of Qinghai is 6843 meters and the average elevation of the whole province is over 4000 meters. The elevation of western Qinghai is lower than the eastern part and the southern part is lower than the northern part. The great mountains form the basic skeleton of the province's physiognomy. The average elevation of Qingnan Plateau which is in south of Qinghai is over 4000 meters, accounting for more than half of the total area of the province. The elevation of Huanghe-Huangshui valley is much lower, which is about 2000 meters. Since locates in the deep inland and far from the sea, Qinghai province has the plateau continental climate which has long sunshine duration and strong radiation, long winter and cool summer. The precipitation is small on the whole and has large regional difference and is decreasing from the southeast to the northwest The annual precipitation in most parts of the province is small than $400 \mathrm{~mm}$.

The population of Qinghai is small, and the distribution of 
population in the province varies with the space. Xining and Haidong account for only 3\% area of Qinghai and bare more than $60 \%$ population of the whole province. Restricted by natural, social and historical conditions, most part of Qinghai province is underdeveloped and with backward economy. Qinghai is one of the five pastoral areas in China and has a large area of grassland. The grassland is mainly distributed in Qingnan plateau, Qilian Mountain and the southeastern edge of Qaidam basin. Farmland accounts for only about $1 \%$ of the province's total land area and is mainly distributed in Huangshui and the Yellow River basin area on the east of Riyue Mountain. Besides, Qaidam basin, Gonghe basin, and northern Qilian Mountain edges and river valley in the south of Qingnan also distributes a small area of farmland.

Eco-environment of Qinghai province is vulnerable. Influenced by global warming and human factors, the eco-environment in Qinghai is deteriorating, especially the grassland desertification, glaciers melting, snow line rising, lakes and wetlands atrophy, has significantly harmed regional ecological function. As an important natural resource in Qinghai, grassland is mainly distributed in high altitude area with harsh climate conditions. Because of the simple structure and poor stability, once be destroyed, it is hard to recover the grassland ecosystem. Recent decades, a number of grassland in Qinghai has degraded and turned to desert as a consequence of overgrazing and reclamation. With grassland degradation, the rats and pests are rampant and grassland productivity declined rapidly. Wetlands in Qinghai are unique and important plateau wetlands. Three-river source region is the largest and highest natural wetland of China. Since the 1990s, due to the increase of artificial water facilities and other human activities, natural wetland ecosystem has deteriorated. As a result, downstream of rivers, lakes, swamps are shrinking and drying up, wetland degradation trend intensified. With the disappearance of the alpine marsh vegetation, the biodiversity and ecosystem diversity decreased (Xiu, 2016).

\section{DATA}

\subsection{National Geographic Conditions Data}

National Geographical Condition Census project collects fundamental information of the whole country's natural and artificial conditions from the perspectives of geographic space distribution rules and distribution status. The Qinghai provincial geographical condition census started since April 2013 and lasted for more than three years. With advanced space observation technologies and 2500 people's hard work, the spatial distribution and current situation of geographic conditions in Qinghai has been acquired. From 2016, the monitoring of national geographical condition began. Monitoring of national geographic conditions refers to, from the perspective of geographic space, analyzing, studying and describing national conditions, recording and analyzing the changes of national geographic conditions, carrying out dynamic monitoring on important geographic features, releasing monitoring results and analysis reports in a timely manner so as to provide a basis for scientific development.

The location, scope and area of landform, vegetation cover, water area, desert and open ground, etc., are investigated in national geographic condition census and abundant geospatial data has been acquired. The data is classified into 12 first-level categories, 58 subcategories and 94 third-level categories. The geographic conditions data of Qinghai contains 2.1 million high accuracy polygons, which seamlessly covers the whole province with no gap. Geographic condition data mainly includes landform data, land cover data, element of geography data and statistic data. Landform data includes high accuracy DEM and Slope. Land cover data depicts the location and scope of farmland, garden, forest, grassland, water area, building, roads, and bare land. Element of geography data includes geoinformation of roads, facilities, river system and geographical unit. Based on all the survey data above, the area, length and proportion of the feature are obtained to form the statistic data.

\subsection{Thematic Data}

Thematic data includes the amount of water resource in each prefecture and pollution emissions in each county in Qinghai from 2014 to 2016, meteorological observation points with temperature and precipitation of each point from 2014 to 2016 and soil erosion map of Qinghai.

\section{METHODS}

\subsection{Evaluation Procedure}

The eco-environment status evaluation and change analysis of Qinghai is implemented as the flowchart in Figure 1. According to Technical Criterion for Ecosystem Status Evaluation released by Ministry of Environmental Protection in 2015, the status of eco-environment can be depict by the ecological index. In this paper, spatiotemporal change of eco-environment status in Qinghai was revealed by calculating the ecological index which is weighted by five sub-indices (biological richness index, vegetation coverage index, water network denseness index, land stress index and pollution load index) of 413 towns in Qinghai from 2014 to 2016 based on national geographic conditions census and monitoring data, Landsat- 8 images, and thematic data. Before the evaluation, In addition, the thematic data should be standardized and spatialized to insure they can be processed with geographic conditions data. Before the evaluation, national geographic conditions census and monitoring data has been pre-processed to appropriate with the land cover classification indicators in Technical Criterion for Ecosystem Status Evaluation(Tang, et al. 2016). In addition, the thematic data have been standardized and spatialized to insure they can be processed with geographic conditions data.

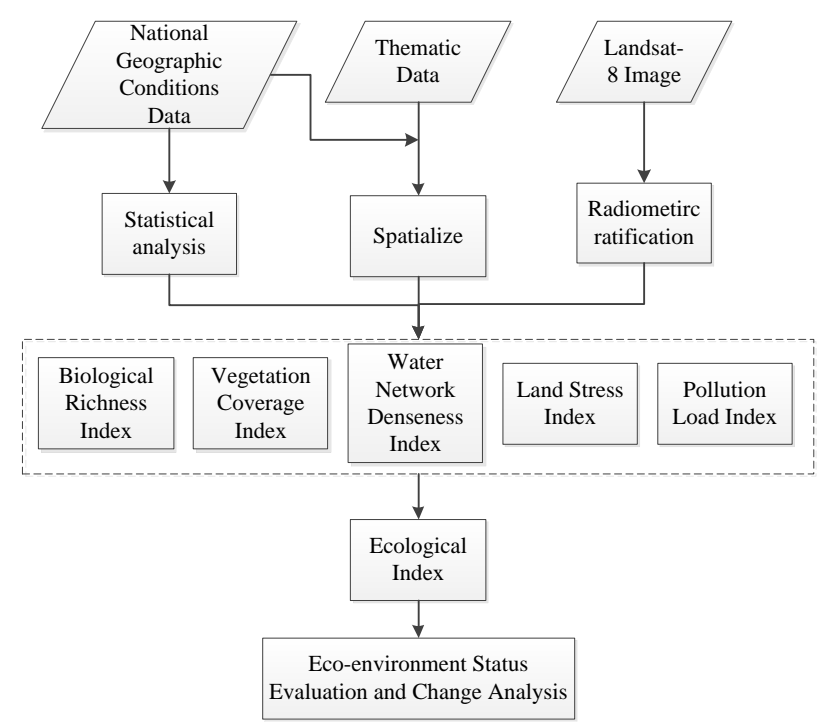

Figure 1. Procedure of eco-environment status evaluation 


\subsection{Indices}

4.2.1 Habitat Quality Index: Habitat Quality Index reflects the quality of habitat and is calculated based on the area of land caver. The land cover classification indicators of Habitat Quality Index in Technical Criterion for Ecosystem Status Evaluation are highly related to the national geographic conditions data but still have discrepancy. To eliminate this discrepancy, national geographic conditions census and monitoring data should be pre-processed to appropriate with the land cover classification indicators in Technical Criterion for Ecosystem Status Evaluation (Chen, et al. 2013; Yan, et al. 2016). Table 1 depicts the indicators and their weight based on national geographic conditions census and monitoring data.

\begin{tabular}{|c|c|c|c|}
\hline $\begin{array}{l}\text { First-level } \\
\text { category }\end{array}$ & Weight & Subcategory & Weight \\
\hline \multirow{3}{*}{ Forest } & \multirow{3}{*}{0.35} & Arbor & 0.6 \\
\hline & & Shrub & 0.25 \\
\hline & & Other forest & 0.15 \\
\hline \multirow{3}{*}{ Grassland } & \multirow{3}{*}{0.21} & High coverage grass & 0.6 \\
\hline & & Medium coverage grass & 0.3 \\
\hline & & Low coverage grass & 0.1 \\
\hline \multirow{2}{*}{ Farmland } & \multirow{2}{*}{0.11} & Paddyfield & 0.6 \\
\hline & & Dryland & 0.4 \\
\hline \multirow{4}{*}{ Water area } & \multirow{4}{*}{0.28} & River & 0.1 \\
\hline & & Lake & 0.3 \\
\hline & & Wetland & 0.5 \\
\hline & & Glacier and snow cover & 0.1 \\
\hline \multirow{3}{*}{$\begin{array}{l}\text { Construction } \\
\text { land }\end{array}$} & \multirow{3}{*}{0.04} & Road and structure & 0.3 \\
\hline & & Building & 0.4 \\
\hline & & Unearthed grounds & 0.3 \\
\hline \multirow{5}{*}{ Bare land } & \multirow{5}{*}{0.01} & Sandy surface & 0.2 \\
\hline & & Saline and alkaline land & 0.3 \\
\hline & & Gravel surface & 0.2 \\
\hline & & Rock surface & 0.2 \\
\hline & & Earth surface & 0.1 \\
\hline
\end{tabular}

Table 1. Indicators and weights of Habitat Quality Index

4.2.2 Vegetation Coverage Index is depicted by optimize soil-adjusted vegetation index (OSAVI) which can avoid the influence of soil. The index is calculated by Band 5 and Band 4 of Landsat-8.

4.2.3 Water Network Denseness Index is weighted by the length of rivers, the area of lakes and the amount of water resource in each town. The length of river and area of lakes are all extracted from national geographic condition data while the amount of water resource is collected from water department However, the water department can only provide amount of water resource data in each prefecture. To get the water resource data that can reach the accuracy of the evaluation, the collected data has been prorated to each town based on the water area information in national geographic condition data.
4.2.4 Land Stress Index is weighted by area of severe erosion land, area of moderate erosion land and area of construction land. The area construction land is extracted from national geographic condition data while area of erosion land is extracted from soil erosion map of Qinghai

4.2.5 Pollution Load Index is weighted by amount of pollution emissions; include emission of sulphur dioxide, ammonia-nitrogen, smoke powder, chemical oxygen demand and oxynitride. Since only countries' pollution emission data can be collected from environmental protection department, the data has been prorated to each town based on the residential and industrial land area in national geographic condition data

4.2.6 Ecological Index is weighted by the five sub-indices above.

Ecological Index $=0.35 \times$ Habitat Quality Index $+0.25 \times$ Vegetation Coverage Index $+0.15 \times$ Water Network Denseness Index+0.15x (100 - Land Stress Index $)+0.10 \times$ (100-Pollution Load Index)

\section{RESULT AND ANALYSYS}

The indices of Qinghai eco-environment status evaluation in 2016 are shown in Figure1. Except for ecology index, the five sub-indices also have obvious spatial distribution characteristics. In addition to individual regions, the biological richness index and vegetation coverage index of eastern part of Qinghai is better than the western part as well as the southern part is better than the northern part. The water network denseness index is higher in the western part of Yushu prefecture, the northwestern part of Guoluo prefecture and Qinghai Lake. The land stress index is higher in the western part of Yushu prefecture, the most part of Haixi prefecture, the middle part of Hainan prefecture, and part of Xining and Haidong where Yellow River and Huangshui River flow through. Moreover, the land stress in Yushu prefecture is mainly because of frost-thaw erosion, while Haixi prefecture and Hainan prefecture is mainly caused by wind erosion, and Xining and Haidong is mainly because of water erosion and human activities. The pollution load index is higher in areas where bare a large population density, such as Xining and Haidong. 


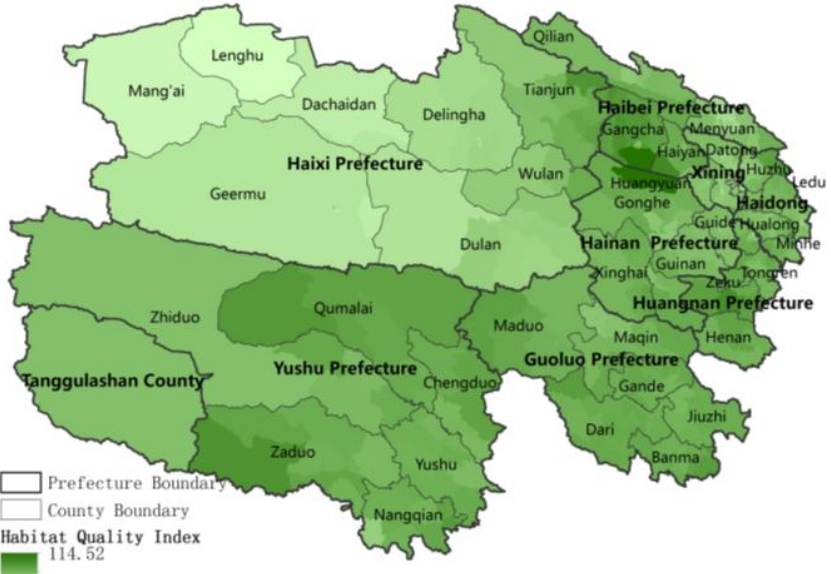

a. Habitat Quality index

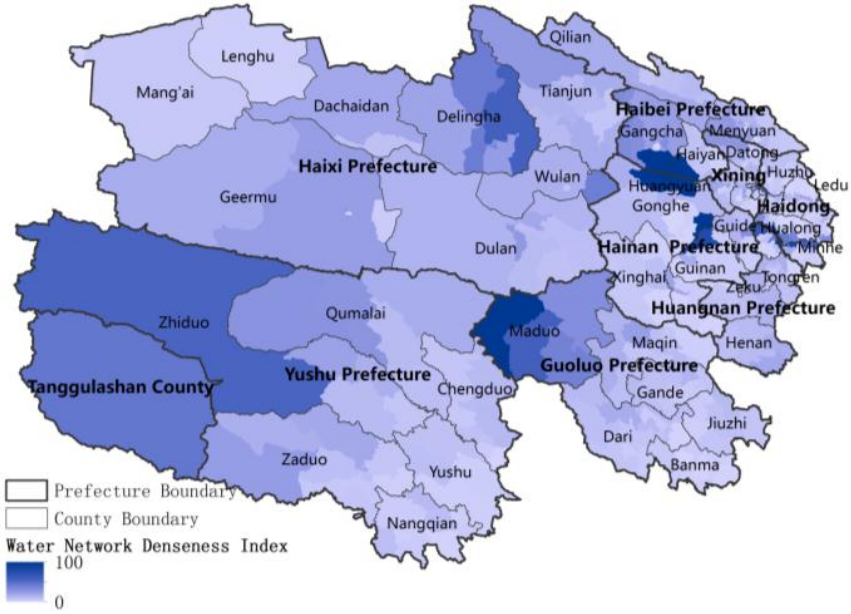

c. Water Network Denseness Index

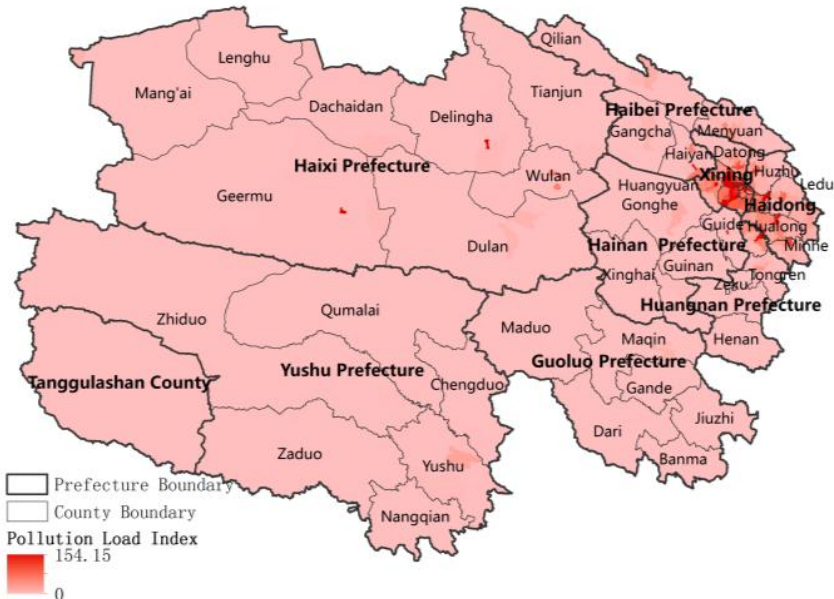

e. Pollution Load Index

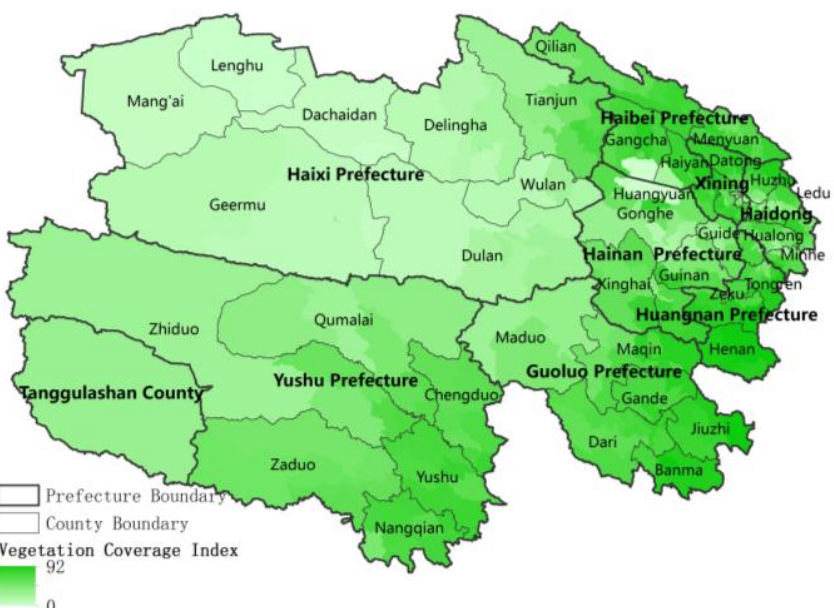

b. Vegetation Coverage Index

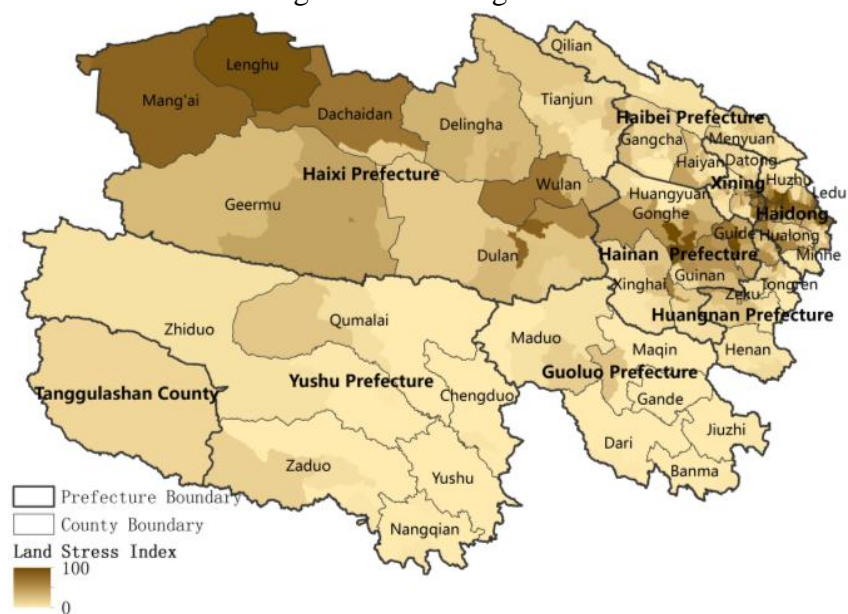

d. Land Stress Index

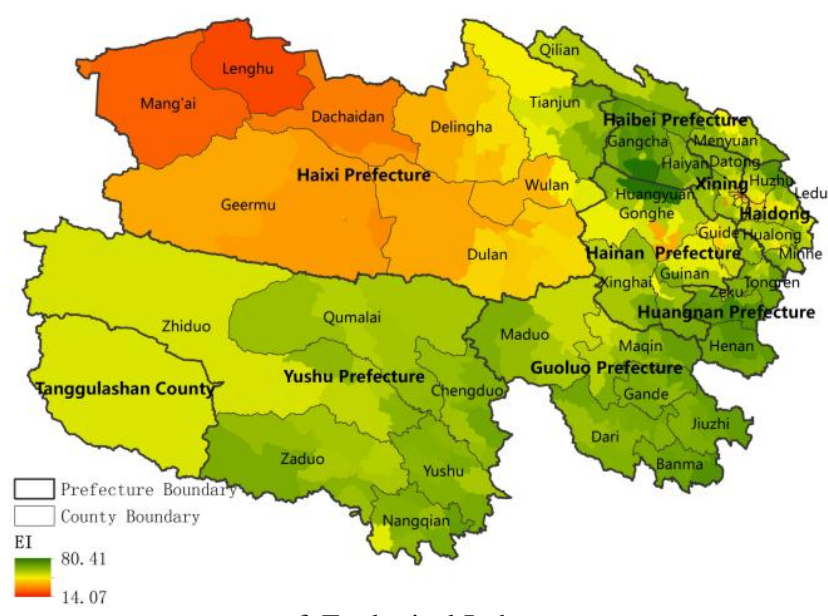

f. Ecological Index

Figure 2. Eco-environment indices of Qinghai in 2016

Eco-environment status of Qinghai in 2016 is shown in Figure 3 and the statistical data is shown in Table 2. The evaluation result shows that the eco-environment status in Qinghai is generally in a fine condition and eco-environment status of most towns in Qinghai are in a fine condition. The eco-environment in Qinghai has significant regional differences: the eastern part of Qinghai is better than the western part and the southern part is better than the northern part for different factors. The high precipitation and vegetation coverage in the southeastern part with the slight pollution and soil erosion leads to an excellent eco-environment status. Southwestern part has a dense water network and slight pollution, however, the serious soil erosion and low vegetation coverage makes the eco-environment just in a fine status. Due to the low precipitation, low vegetation coverage, serious soil erosion and high pollutant emission, the southwestern part which located in Qaidam basin bares a poor eco-environment status. 


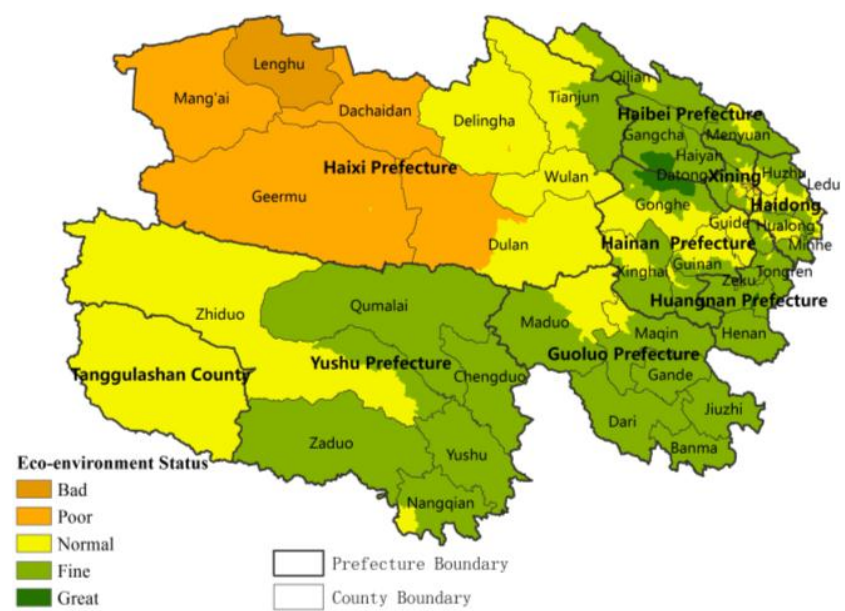

Figure 3. Eco-environment status of Qinghai in 2016

\begin{tabular}{|l|r|r|r|r|r|}
\hline status & \multicolumn{1}{|c|}{ Great } & Fine & \multicolumn{1}{c|}{ Normal } & Poor & \multicolumn{1}{l|}{ Bad } \\
\hline $\begin{array}{l}\text { number of } \\
\text { towns }\end{array}$ & 3 & 234 & 130 & 33 & 5 \\
\hline
\end{tabular}

Table 2. Statistical data of eco-environment status

Eco-environment change of Qinghai form2014 to 2016 is shown in Figure 4 and the statistical data of eco-environment status change is shown in Table 3. The ecological index of Qinghai has gradually risen from 2014 to 2016 and eco-environment status of most towns are meliorate of unchange, which indicates that the ecological restoration project implemented in Qinghai has promoted the eco-environment status improving. Generally speaking, land stress changes slowly, therefore the eco-environment status

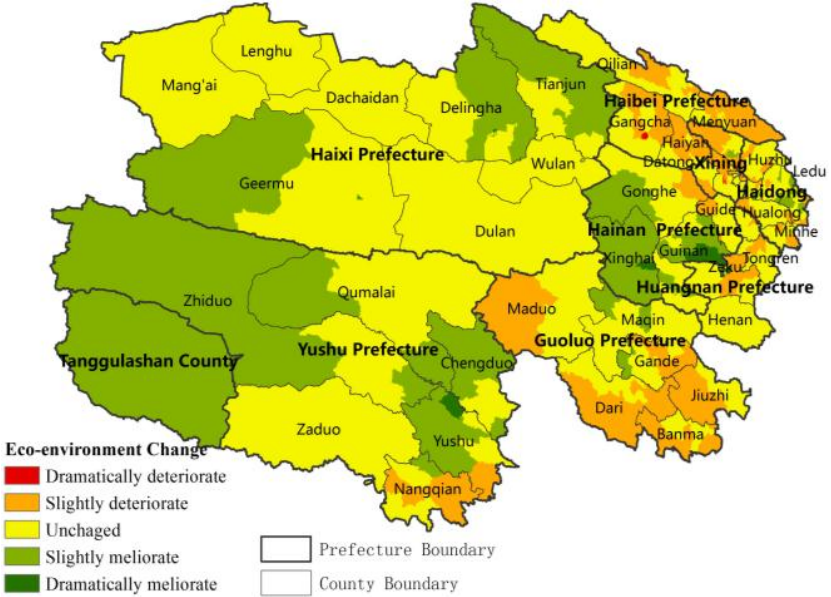

Figure 4. Eco-environment change of Qinghai form2014 to 2016

changing in a short term mainly caused by meteorology, vegetation coverage and human factors, which together have an impact on pollution load and water recourse. In 2016, the precipitation in the northeastern and southern part of Qinghai was lower than that in 2014 and the vegetation coverage and water resources were also lower, so the eco-environment status in these parts got slightly worse. With smaller region area, larger population and rapid economic development, the communities in urban areas has an unstable eco-environment status caused by human activities. The obvious eco-environment status changes were happened in these regions.

\begin{tabular}{|c|c|c|c|c|c|}
\hline $\begin{array}{c}\text { Eco-environment } \\
\text { change }\end{array}$ & $\begin{array}{c}\text { Dramatically } \\
\text { meliorate }\end{array}$ & $\begin{array}{c}\text { Slightly } \\
\text { meliorate }\end{array}$ & Unchanged & $\begin{array}{c}\text { Slightly } \\
\text { deteriorate }\end{array}$ & $\begin{array}{c}\text { Dramatically } \\
\text { deteriorate }\end{array}$ \\
\hline number of towns & 10 & 61 & 224 & 112 & 6 \\
\hline
\end{tabular}

Table 3. Statistical data of eco-environment status change

\section{CONCLUSION}

The eco-environment status evaluation based on national geographic conditions census and monitoring data can improve both the time and space precision. The eco-environment status with high space precise and multi-indices is a key basis for environment protection decision-making. However, the collection of thematic data has hysteresis, which may delay the eco-environment status evaluation. Besides, the accuracy of thematic is low and cannot match with national geographic condition data which will affect the accuracy of eco-environment status evaluation to some extent. If more accurate thematic data can be collected, the evaluation result can be more reliable.

\section{REFERENCES}

Bassett, S., 2015. San Juan River Historical Ecology Assessment: Changes in Channel Characteristics and Riparian Vegetation. 10.13140/RG.2.1.2471.3208.

Chen, Y. J., Chen, W. H., Chen, H. H., Chen, F., Yan, L. I., \& Jiang, C. M., 2016. The ecological environment quality evaluation of xiamen - based on the first geographical conditions census data in 2013. Journal of Fujian Normal University, 32(03):144-151.
Jia, H. C., Cao, C. X., Ma, G. R., Bao, D. M., Wu, X. B., Xu, M., Zhao, J. and Tian, R., 2011. Assessment of wetland ecosystem health in the source region of yangtze,yellow and yalu tsangpo rivers of qinghai province. Wetland Science, 9(3), 209-217.

Tang, W., Wang, D., F., Wen, X., H., 2016. Research of the Method to Integrate National Geographic Condition Survey Data with Ecological Environment. Surveying and Mapping, (6):255-258.

Xiu, R., N., 2016. Research about the construction of ecological civilization of Qinghai province. Northwest Minzu University, Lanzhou, CHN.

Yan, L. I., Chen, W. H., Chen, Y. J., Chen, H. H., \& Jiang, C. M (2016). Evaluation on eco-environment of xiamen based on the first national geography census data. Journal of Subtropical Resources \& Environment, 11(2):67-75.

Yang, R., K., 2017. Exploration and practice of eco-civilization system reform in Qinghai Province.

Zhao, S. M., Wang, D. W., \& Wang, J. T., 2013. Evaluation on the eco-environmental status of Kunming and countermeasures. Environmental Science Survey, 32(03):102-105. 